\title{
Coxsackievirus B4 Infection of Murine Foetal Thymus Organ Cultures
}

\author{
Fabienne Brilot, ${ }^{1,2}$ Hela Jaïdane, ${ }^{,, 3}$ Vincent Geenen, ${ }^{1}$ and Didier Hober ${ }^{2 *}$ \\ ${ }^{1}$ Centre d'Immunologie de Liège (CIL), Institut de Pathologie 4, Université de Liège, Liège (Sart-Tilman), \\ Belgium \\ ${ }^{2}$ Laboratoire de Virologie / UPRES EA3610, Faculté de Médecine, Université Lille 2, Lille, France \\ ${ }^{3}$ Laboratoire de Virologie Lab-MDT-01, Faculté de Pharmacie de Monastir, Monastir, Tunisia
}

The infection of foetal thymus with coxsackievirus B4 (CV-B4) E2 has been studied ex vivo by using CD-1 mice on foetal day 14, as a ready source of organs for experimentation to investigate the hypothesis of the role of thymic viral infections in the pathogenesis of type 1 diabetes. The replication of CV-B4 E2 in murine foetal thymus organ cultures has been demonstrated by evaluating the levels of positive- and negativestranded viral RNA in cells by using a real-time quantitative RT-PCR method and by determining titres of infectious viral particles in culture supernatants for 7 days post-infection (p.i.). Staining of tissue sections with an anti-cytokeratin antibody and haematoxylin-eosin showed that CV-B4 infection had no visible effect on cell survival and organ integrity. Cell counts in mock- and virus-infected foetal thymus organ cultures increased from day 1 through day 7 , and live cell numbers were comparable in both conditions as shown by Trypan blue exclusion test and 7-amino-actinomycin D staining of thymocytes. Compared with controls on day 7 p.i., cytofluorometric analyses on cells from CV-B4 E2-infected foetal thymus organ cultures displayed a marked increase in the percentage of the most immature $\mathrm{CD} 3^{-} \mathrm{CD} 4^{-} \mathrm{CD} 8^{-}$thymocytes, and a decrease in the percentage of immature $\mathrm{CD} 3^{-} \mathrm{CD} 4^{+} \mathrm{CD} 8^{+}$ cells, together with an increase in the percentage of mature $\mathrm{CD}^{+} \mathrm{CD}^{+}$and $\mathrm{CD} 3^{+} \mathrm{CD}^{+}$cells. These data show that CV-B4 E2 disturbs T-cell maturation and differentiation processes in infected murine foetal thymus organ cultures and provide evidence of a suitable system to investigate the effect of viruses in T-cell differentiation. J. Med. Virol. 80:659-666, 2008. ๑ 2008 Wiley-Liss, Inc.

KEY WORDS: CV-B4 E2; murine foetal thymus organ cultures; T-cell differentiation

\section{INTRODUCTION}

Type 1 diabetes is a multifactorial disease that obeys to a genetic predisposition, determined by a balance between susceptibility and resistance alleles, and is triggered by environmental factors such as viruses. Seroepidemiological data implicated largely enteroviruses, especially type B coxsackieviruses (CV-B), in type 1 diabetes development [Helfand et al., 1995; Hyöty et al., 1995] and several studies observed the presence of nucleotide sequences of those viruses in the blood of patients with that disease (reviewed by Hyöty et al., 2002). Among CV-B or enterovirus genus, CV-B4 is one of the serotypes most frequently associated with the disease in prediabetic and diabetic patients [Gamble et al., 1973; Chehadeh et al., 2000b]. The diabetogenic strain CV-B4 E2 was isolated from the pancreas of a child who died from diabetic ketoacidosis and was able to induce hyperglycaemia in some susceptible mouse strains [Yoon et al., 1979].

Type 1 diabetes is an autoimmune disease which results from the loss of or defect in immune tolerance establishment [Sinha et al., 1990]. Self-tolerance is initiated in the thymus during T-cell ontogeny [Geenen and Kroemer, 1993; Martens et al., 1996; Geenen et al., 2001], a multi-step process which starts as soon as foetal life. The thymus fulfils this function by two complementary mechanisms: the deletion of $\mathrm{T}$ cells directed against self-antigens presented in the thymic cellular environment (thymic epithelial cells, macrophages and

Fabienne Brilot and Hela Jaïdane contributed equally to this work.

*Correspondence to: Didier Hober, Service de Virologie/UPRES EA3610, Bâtiment Paul Boulanger, CHRU Lille, 59037 Lille, France. E-mail: dhober@chru-lille.fr

Accepted 16 July 2007

DOI 10.1002/jmv.21016

Published online in Wiley InterScience

(www.interscience.wiley.com) 
dendritic cells) by major histocompatiblity complex (MHC) proteins, and the generation of self-antigen specific regulatory $\mathrm{T}$ cells $\left(\mathrm{T}_{\mathrm{REG}}\right)$.

It has been reported that a viral infection of thymus can facilitate immune tolerance to antigens of that infectious agent, which can result in viral persistence [Korostoff et al., 1990; King et al., 1992]. Vertical transmission of CV-B associated with foetal thymus infection has been reported [Iwasaki et al., 1985; Lozovskaia et al., 1997]. In addition, it has been shown that enterovirus infections in utero may induce $\beta$-cell autoimmunity [Otonkoski et al., 2000], and that CV-B4 infection during pregnancy was a risk factor for childhood-onset type 1 diabetes [Dahlquist et al., 1995; Hyöty et al., 1995].

It has been suggested that foetal infection with CV-B may initiate autoimmunity or cause persistent infection that may lead to a progressive $\beta$-cell destruction and thus could play a role in the pathogenesis of type 1 diabetes [Dahlquist et al., 1995]. Furthermore, massive thymic depletion and/or CV-B4 E2-induced abnormal lymphocyte maturation have been linked to autoimmunity with possible insulitis and hyperglycaemia in mice models [Chatterjee et al., 1992; Shih et al., 2004].

These data suggest a role for CV-B4 infection of the thymus in the emergence of type 1 diabetes in individuals predisposed genetically. Through thymus infection, CV-B4 may severely impair the physiologic function of that organ. In this perspective, it has been demonstrated previously that CV-B4 can persistently infect primary cultures of human thymic epithelial cells and modulate the profile of LIF, IL-6 and GM-CSF secretion by these cells [Brilot et al., 2002]. It has also been observed that CV-B4 infection of cultures of human foetal thymus dissected into small pieces resulted in a dramatic depletion of immature $\mathrm{CD} 4^{+} \mathrm{CD} 8^{+}$thymocytes with an increased expression of MHC I that is one of the three-molecular complex TCR/MHC/self-antigen actors responsible for negative selection of self-reactive $\mathrm{T}$ cells in the thymus [Brilot et al., 2004].

Mice constitute a universal model for studying several aspects related to type 1 diabetes that are difficult to investigate in humans. It has been observed that CV-B4 E2 can infect the thymus in vivo in a mouse model of virus-induced type 1 diabetes [Chatterjee et al., 1992], which resulted in a significant increase in $\mathrm{CD} 4^{-} \mathrm{CD} 8^{-}$ thymic T cells, suggesting that CV-B4 E2 can induce an abnormal $\mathrm{T}$ lymphocyte maturation that may be involved in the development of type 1 diabetes.

To investigate further the hypothesis of the role of thymic viral infections in the pathogenesis of type 1 diabetes, it is essential to have a system which is easy to handle and providing ready access to a source of foetal thymus for experimentation. Therefore we developed a model of murine foetal thymus organ cultures infected with CV-B4 E2, in order to study the interaction of CVB4 E2 with that organ and to assess whether such an infection can result in a disturbance of the pattern of thymocyte populations ex vivo.

\section{MATERIALS AND METHODS}

\section{Animals and Tissue Collection}

Adult CD-1 outbred mice were obtained from the Centre d'Elevage Janvier (Le Genest St Isle, France) and bred in the animal facility of the Institute of Pathology at the University of Liege. Mice were mated overnight (16 hr) and foetuses were removed at day 14 of gestation (plug date $=$ day 0 ). The experimental procedures were carried out in accordance with the Ethical Committee on Animal Experimentation of the University of Liege.

\section{Virus}

The diabetogenic strain CV-B4 E2 (provided by J.W. Yoon, Julia McFurlane Diabetes Research Center, Calgary, Alberta, Canada) was generated as described previously [Brilot et al., 2002]. Briefly, CV-B4 E2 was grown in Vero cells (American Type Culture Collection, Manassas, VA) in Eagle's Minimum Essential Medium (Cambex, Verviers, Belgium) supplemented with 10\% foetal calf serum (FCS) (a generous gift from Dr. M. De Smedt, University of Gent, Belgium). Supernatants were collected 3 days after inoculation, clarified at $1,200 \mathrm{~g}$ for $10 \mathrm{~min}$, divided into aliquots and stored at $-80^{\circ} \mathrm{C}$. Virus titres in stocks were determined on Vero cells by limiting dilutions assay for $50 \%$ tissue culture infectious doses (TCID 50 ) by the method of Reed and Muench [1938].

\section{Foetal Thymus Organ Cultures}

Foetal thymus organ cultures were performed as described previously [Plum et al., 1995; Kecha et al., 2000]. Briefly, single foetal thymus lobes from CD-1 mice on foetal day 14 were directly transferred into CV-B4 E2 stocks at a $10^{4} \mathrm{TCID}_{50}$ per lobe for $4 \mathrm{hr}$ at $37^{\circ} \mathrm{C}$ in a $5 \% \mathrm{CO}_{2}$ incubator. Lobes were then transferred onto sterile filters of $0.8 \mu \mathrm{m}$ pore size (Nucleopore Costar, Cambridge, MA) placed on Gelfoam (Pharmacia-Upjohn Kalamazoo, MI) rafts in $700 \mu \mathrm{l}$ of Iscove's modified Dulbecco's medium (Cambex) supplemented with L-glutamine $(2 \mathrm{mM}), \operatorname{HEPES}(25 \mathrm{mM})$, non essential amino acids (1\%), sodium pyruvate (1\%), streptomycin $(100 \mu \mathrm{g} /$ $\mathrm{ml})$, penicillin $(100 \mathrm{UI} / \mathrm{ml})$ (all reagents purchased from Cambex), and FCS (10\%), in 24-well culture plates. Mock-infected foetal thymus organ cultures were incubated $4 \mathrm{hr}$ in non-infected Vero cells culture supernatant then treated in the same way and served as a negative control. Foetal thymus organ cultures were incubated 7 days, and the medium was collected and changed on days 0,3 and 7 post-infection (p.i.). At the end of the culture, individual thymus lobes were dispersed and cell suspensions were prepared by crushing. Living cells were estimated by Trypan blue dye exclusion test. Cells were also washed and stained for CD3, CD4, CD8, and 7-amino-actinomycin D (7-AAD, BD Pharmingen, San Diego, CA) and then examined by fluorescenceactivated cell sorting (FACS). 


\section{Quantitative RT-PCR for CV-B4 E2}

CV-B4 E2 positive- and negative-stranded RNA in foetal thymus organ cultures were quantified at days 0,3 and 7 p.i. by two-step quantitative RT-PCR by using the TaqMan fluorogenic detection system with AmpliTaq Gold reagents (Applied Biosystems, Foster City, CA) as previously described [Brilot et al., 2004]. Briefly, total RNA was extracted from thymic lobes with RNeasy minikit (Qiagen Valencia, CA), resuspended in water, and quantified by using RiboGreen quantification kit (Invitrogen Carlsbad, CA) according to the manufacturer's instructions. Total RNA was measured by a quantitative RT-PCR for rRNA expression with the TaqMan rRNA control reagent (Applied Biosystems). Positive- and negative-strand-CV-B4 E2 specific RT was carried out with $12 \mathrm{ng}$ of $\mathrm{rRNA}$ and either the reverse or forward primer at $48^{\circ} \mathrm{C}$ for $30 \mathrm{~min}$. PCR was performed under universal cycle conditions $\left(10 \mathrm{~min}\right.$ at $95^{\circ} \mathrm{C}$, 40 cycles of $15 \mathrm{sec}$ at $95^{\circ} \mathrm{C}$ and $1 \mathrm{~min}$ at $60^{\circ} \mathrm{C}$ ) on an ABI Prism 7700 sequence detector (Applied Biosystems). The following primers, used to detect CV-B4 $\mathrm{E} 2$, were located within the enterovirus $5^{\prime}$-nontranslated region, which is highly conserved among enterovirus serotypes: CV-B4 E2 forward (5'-GTAGTCCTCCGGCCC CT-3') and CV-B4 E2 reverse (5'-AATTGTCACCATAAGCAGCCA-3'). The sequence of the probe was 5'-VIC-ATGCGGCTAATCCTAACTGCGGAG-TAMRA$3^{\prime}$ (Applied Biosystems). The RNA copy number in each sample was determined as described elsewhere by a standard curve generated from increasing copy number of a synthetic transcript corresponding to $435 \mathrm{nt}$ of the CV-B4 E2 genome [Brilot et al., 2004]. Briefly, $435 \mathrm{nt}$ within the enterovirus $5^{\prime}$-nontranslated region were reverse transcribed and amplified with primers described previously [Leparc et al., 1994]. The PCR product was cloned in pCR2.1-TOPO (Invitrogen), sequenced, and subcloned to two different $\mathrm{T} 7$ promotercontaining pBluecript II $\mathrm{KS}(+)$ vectors to obtain a positive and negative strand after in vitro transcription. Sense and anti-sense synthetic RNA generated with a T7 Megascript RNA transcription kit (Ambion) were measured by spectrophotometry and diluted to obtain a standard curve. The absence of contaminating DNA from plasmid in standards and genomic DNA in samples was checked by RT-PCR without the reverse transcriptase enzyme. Primers and probes were designed with the PrimerExpress software, and the data were analysed with Sequence Detection System SDS 1.9.1 (both from Perkin-Elmer, Boston, MA).

\section{Quantitation of Infectious Virus in Foetal Thymus Organ Cultures Supernatants}

The ability of murine foetal thymus organ cultures to yield infectious viral particles was measured by ReedMuench's method [Reed and Muench, 1938] performed in Vero cells. Viral titres were determined in culture supernatants collected on days 0,3 and 7 p.i. and expressed as $\mathrm{TCID}_{50} / \mathrm{ml}$.

\section{Immunohistochemistry and Histology}

On day 7 p.i., single thymus lobes were embedded in Tissue-TEK ${ }^{\circledR}$ (Sakura) and frozen at $-80^{\circ} \mathrm{C}$. Five $\mu \mathrm{m}$ tissue sections were fixed for $10 \mathrm{~min}$ in $4 \%$ paraformaldehyde at $4^{\circ} \mathrm{C}$ and washed in buffer (Tris- $\mathrm{HCl} 0.5 \mathrm{M} \mathrm{pH}$ 7.6; $\mathrm{NaCl} 9 \%$; Tween $202 \%, \mathrm{NaN}_{3} 2 \%$ in $\mathrm{H}_{2} \mathrm{O}$ ). Slides were incubated in a humidified chamber with rabbit polyclonal anti-mouse cytokeratin (CK) (A575, Dako, Glostrup, Denmark) for $2 \mathrm{hr}$ at room temperature. The slides were washed and stained with secondary antibody FITC-conjugated goat anti-rabbit IgG (Jackson ImmunoResearch Laboratories Inc., West Grove, PA) for $1 \mathrm{hr}$ at room temperature, washed again, and mounted with glycerol-gelatin medium. Slides were examined with a fluorescence microscope (Olympus, France).

Alternatively, $5 \mu \mathrm{m}$ tissue sections were also stained by using routine haematoxylin-eosin staining. Sections were incubated with $0.25 \%$ haematoxylin reagent and 0.5\% eosin (Merck Biosciences, Leuven, Belgium), then dehydrated with graded isopropanol, treated with xylene and mounted with Entellan medium (Merck Biosciences).

\section{FACS Staining and Analyses}

After 7 days of culture, dispersed thymocytes from foetal thymus organ cultures were washed, pelleted, resuspended in $50 \mu \mathrm{l}$ of monoclonal antibodies and incubated for $30 \mathrm{~min}$ at $4^{\circ} \mathrm{C}$. After incubation, cells were rinsed, pelleted, and resuspended in $200 \mu$ l of phosphatebuffered saline-2\% FCS for FACS analysis. Two- or three-colour FACS staining was performed with the indicated combinations of the following antibodies: antiCD3-peridinin-chlorophyll protein (PerCp), anti-CD4phycoerythrin (PE), and anti-CD8-fluorescein isothiocyanate (FITC) (all from BD Pharmingen). Viability was assessed with 7-AAD (BD Pharmingen). Samples were examined immediately after staining on a FACSCalibur by using CELLQuest software (Becton Dickinson).

\section{Statistical Analyses}

Statistical analyses were performed using MannWhitney's nonparametric test. The data are expressed as means \pm standard deviations (SD).

\section{RESULTS}

\section{Murine Foetal Thymus Organ Cultures Undergo Cellular Growth and Differentiation In Vitro}

In order to assess the growth of thymic lobes in culture, the number of viable cells was evaluated on days 0 and 7. Foetal thymic lobes were isolated from CD-1 mice foetus on the 14th day of gestation and contained a mean of $16,006 \pm 8,260$ cells per lobe $(n=37)$. After 7 days of culture, the number of cells per lobe was multiplied by 9 , with a mean of $141,667 \pm 79,400$ cells per lobe $(n=9)$ in mock-infected foetal thymus organ cultures for example (Table I), showing proliferation of thymocytes within the lobes during culture. The cell 
TABLE I. Cell Viability in Mock- and CV-B4 E2-Infected Foetal Thymus Organ Cultures at 7 Days Post-Infection

\begin{tabular}{lcc}
\hline & $\begin{array}{c}\text { Number of living cells by Trypan } \\
\text { Blue dye exclusion test }(\mathrm{n}=9)\end{array}$ & $\begin{array}{c}\text { Percentage of living cells by } \\
\text { 7-AAD staining }(\%)(\mathrm{n}=6)\end{array}$ \\
\hline Mock & $141,667 \pm 79,402$ & $87.37 \pm 9.62$ \\
CV-B4 E2 & $128,056 \pm 53,906$ & $86.61 \pm 6.36$ \\
\hline
\end{tabular}

Results are expressed as mean $\pm \mathrm{SD}$.

viability began to decline after the first week of culture, which limited the culture period to 7 days in our investigation. A double staining of thymocytes for CD4 and CD8 was then performed and thymocyte subpopulations were analysed by flow cytometry. Results were expressed as percentages of living cells. On day 0 , the majority of thymocytes were $\mathrm{CD} 4^{-} \mathrm{CD} 8^{-}(98 \%)$ with about $1 \%$ of $\mathrm{CD}^{+}$. After 7 days of culture in control cultures, thymocytes differentiated into 4 different subsets: $25 \%$ of thymocytes were $\mathrm{CD} 4^{-} \mathrm{CD} 8^{-}, 52 \%$ were $\mathrm{CD}^{+} \mathrm{CD}^{+}, 15 \%$ were $\mathrm{CD}^{+}$and $8 \%$ were $\mathrm{CD} 8^{+}$, confirming successful thymocyte differentiation in foetal thymus organ cultures.

\section{CV-B4 E2 Infects Murine Foetal Thymus Organ Cultures}

Virus replication in thymic lobes. Amplification and quantification of CV-B4 E2 positive- and negativestranded RNA by RT-PCR made it possible to determine whether the virus infected the thymic lobes and whether it was replicating. Table II shows that the number of copies of positive-stranded CV-B4 E2 RNA markedly increased between day 0 and day 3 , reached a peak on day 3 , and then decreased between day 3 and day 7 p.i. The same pattern of expression was observed for CVB4 E2 negative-stranded RNA. No CV-B4 E2 positive- or negative-stranded RNA was detected in mock-infected samples (negative control, data not shown).

Virus titration in foetal thymus organ cultures supernatants. Virus titres in supernatants of CV4 E2-infected foetal thymus organ cultures were then assessed. CV-B4 E2 infection led to increased virus titres from day 0 to day 3 (Table III), followed by a dramatic decrease until day 7 p.i., suggesting that a release of virus particles occurred during the first days of the culture. Titration of virus in supernatants of mockinfected foetal thymus organ cultures was also performed and no viral particle was detected in these samples (data not shown).
Organ integrity after CV-B4 E2 infection. To investigate whether CV-B4 E2 could impair thymus integrity, histological staining of thymic lobes sections was performed. Compared to mock-infected foetal thymus organ cultures, CV-B4 E2 infection did not damage the thymus architecture and did not induce obvious cell lysis (Fig. 1). Neither necrosis nor histopathological damage could be observed at higher magnification (Fig. 1). The detection of cellular cytokeratins has previously been shown to identify the network of thymic epithelial cells within the thymus [Brilot et al., 2002], and thus can be used as a marker of tissue integrity. No difference in the cytokeratin staining could be observed between mock- and CV-B4 E2-infected thymic lobes (Fig. 1d,h), suggesting that integrity of the thymus network was preserved after CV-B4 E2 infection. Results were similar in both cortex and medulla.

\section{CV-B4 E2 Infection Disturbs T-cell Differentiation In Vitro}

First, the cell viability was assessed in foetal thymus organ cultures to determine whether the cultures were affected by CV-B4 E2 infection. There was no significant difference in total numbers and percentages of viable cells between mock- and CV-B4 E2-infected foetal thymus organ cultures, using Trypan blue dye exclusion test followed by cell counting or 7-AAD staining followed by flow analysis (Table I).

Then, the effect of CV-B4 E2 infection was studied on thymocyte differentiation in murine foetal thymus organ cultures. Thymocytes are known to evolve from the most immature stage $\mathrm{CD} 3^{-} \mathrm{CD} 4^{-} \mathrm{CD} 8^{-}\left(\mathrm{CD} 3^{-}\right.$ double negative or $\left.\mathrm{CD}^{-} \mathrm{DN}\right)$ to $\mathrm{CD} 3^{-} \mathrm{CD} 4^{+} \mathrm{CD} 8^{+}$ (double positive or $\mathrm{CD}^{-} \mathrm{DP}$ ) before becoming fully mature single positive cells, either $\mathrm{CD}^{+} \mathrm{CD}^{+}$or $\mathrm{CD}^{+} \mathrm{CD}^{+}$. Cells were gated into two main subpopulations: the immature $\mathrm{CD}^{-}$cells or the mature $\mathrm{CD}^{+}$ thymocytes. Results were expressed as percentages of living cells (Fig. 2).

TABLE II. Intracellular Positive- and Negative-Stranded RNA Detection in Murine Foetal Thymus Organ Cultures Infected with CV-B4 E2 at Different Times Post-Infection

\begin{tabular}{lccr}
\hline & \multicolumn{3}{c}{ Number of copies of CV-B4 E2 $\mathrm{RNA}^{\mathrm{a}}($ mean value $\pm \mathrm{SD}, \mathrm{n}=2)$} \\
\cline { 2 - 4 } & Day 0 p.i. & Day 3 p.i. & Day 7 p.i. \\
\hline Positive strands & $2,210.44 \pm 933$ & $31,825.9 \pm 20,044$ & $2,564.7 \pm 3,623$ \\
Negative strands & $3,100.3 \pm 1,780$ & $64,501.2 \pm 17,949$ & $2,975.2 \pm 4,202$ \\
\hline
\end{tabular}

${ }^{a}$ The results were obtained by using quantitative real-time PCR and were expressed as copies/12 ng of ribosomal RNA. 
TABLE III. Release of Viral Particles by Murine Foetal Thymus Organ Cultures Infected with CV-B4 E2 at Different Times Post-Infection

Viral titre in supernatants of CV-B4 E2-infected foetal thymus organ cultures $\left(\mathrm{TCID}_{50} \mathrm{ml}^{-1}\right)^{\mathrm{a}}($ mean value $\pm \mathrm{SD}, \mathrm{n}=4)$

\begin{tabular}{lcc}
\hline Day 0 p.i. & Day 3 p.i. & Day 7 p.i. \\
\hline $440,7 \pm 85,6$ & $4087,1 \pm 1307,9 *$ & $386,5 \pm 501,825$ \\
\hline $\begin{array}{l}\text { aviral titres in culture supernatants were obtained by using Reed-Muench's method on Vero cell cultures. } \\
{ }^{*} P<0.01 .\end{array}$
\end{tabular}

Within immature thymocytes $\left(\mathrm{CD}^{-}\right)$, CV-B4 E2 infection induced a significant decrease in the $\mathrm{CD}^{-} \mathrm{DP}$ DP subset compared with mock-infected cultures $(27 \pm 10.5 \%$ vs. $58 \pm 6.5 \%, \mathrm{n}=4, P<0.05)$, and a significant increase in $\mathrm{CD}^{-} \mathrm{DN}$ thymocytes $(52.5 \pm 13.5 \%$ vs. $21 \pm 6.5 \%, \mathrm{n}=4, P<0.05)$.

As regards mature thymocytes $\left(\mathrm{CD}^{+}\right), \mathrm{CV}-\mathrm{B} 4 \mathrm{E} 2$ infection induced a significant increase in $\mathrm{CD}^{+} \mathrm{CD} 4^{+}$ and $\mathrm{CD}^{+} \mathrm{CD}^{+}$populations compared with mockinfected cultures $(12 \pm 4 \%$ vs. $6.5 \pm 1.5 \%, \quad \mathrm{n}=4$,

Mock-infected FTOC
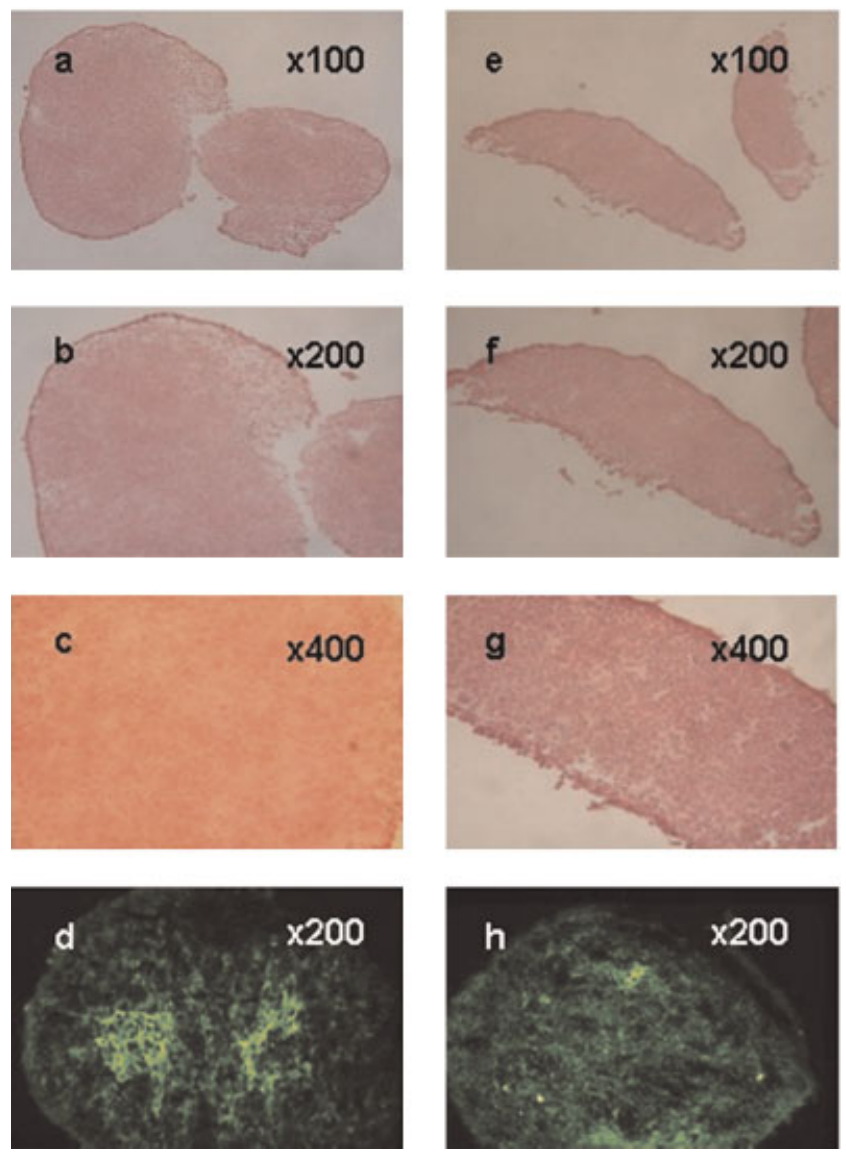

Fig. 1. Effects of CV-B4 on thymus integrity. Foetal thymus organ cultures were infected with mock (a-d) or CV-B4 E2 (e-h) at 104 TCID50 per lobe. At 7 day p.i. haematoxylin-eosin staining of sections was performed (a-c and e-g). Cellular cytokeratins were detected by indirect immunofluorescence staining white signal $(\mathrm{d}, \mathrm{h})$. Representative sections passing through the cortex are shown at three different magnifications: 100_ (a,e), 200_ (b,d,f,h) and 400_ (c,g).
$P<0.05$, and $10 \pm 3.5 \%$ vs. $4 \pm 2 \%, \mathrm{n}=4, \quad P<0.05$, respectively).

\section{DISCUSSION}

Access to human foetal thymus being very limited (forbidden for ethical reasons in the European Union), it is important to develop alternative models as a tissue source for experimentation. In the current work, advantage was taken of thymocyte differentiation ex vivo, in murine foetal thymus organ cultures, to study the infection of that system with CV-B4 E2, and its consequences on thymocyte differentiation.

Foetal thymus organ culture is a method that maintains the three-dimensional architecture of thymus and its cellular composition and allows in vitro growth and differentiation of thymic lobes [Bonyhadi et al., 1995; Kecha et al., 2000; Brilot et al., 2004]. It has been reported that, like human foetal thymus organ cultures, murine foetal thymus organ cultures closely mimic physiological conditions and therefore provide a very appropriate in vitro model and a more rapid means for the study and manipulation of T-cell development compared with alternative in vivo approaches [Plum et al., 1995; Owens et al., 2005]. However, foetal thymus organ cultures have not been used extensively to investigate the consequences of a virus infection, and most studies were performed with HIV and human tissue or chimeric human/mouse tissue [Bonyhadi et al., 1995; Greiner et al., 1996; Choudhary et al., 2005].

Other investigators found 50, 100 and $120 \mathrm{kDa}$ CV-B binding proteins in mouse thymus [Selinka et al., 1998]

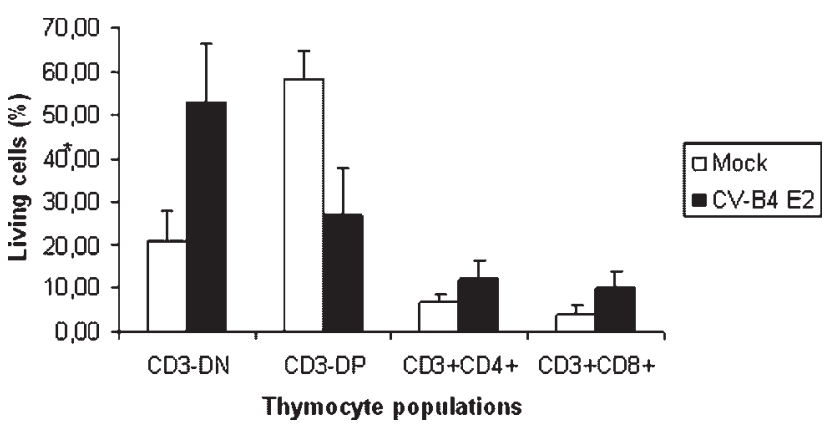

Fig. 2. Effects of CV-B4 infection on thymocyte differentiation Murine foetal thymus organ cultures were infected with CV-B4 E2, then at 7 days post-infection, thymocytes were dissociated and stained with anti-CD3, anti-CD4 and anti-CD8 antibodies and analysed by FACS. Histograms represent the DN and DP thymocyte populations among immature cells $\left(\mathrm{CD} 3^{-}\right)$and the $\mathrm{CD} 4^{+}$and $\mathrm{CD} 8^{+}$thymocyte populations among mature cells $\left(\mathrm{CD}^{+}\right)$. Results are expressed as mean percentages \pm standard deviation, $\mathrm{n}=4 .{ }^{*} P<0.05$ versus mock. DN: double negative $\mathrm{CD} 4^{-} \mathrm{CD} 8^{-}$; $\mathrm{DP}$ : double positive $\mathrm{CD} 4^{+} \mathrm{CD} 8^{+}$. 
and described the in vivo infection of adult mouse thymus by CV-B4 E2 [Chatterjee et al., 1992], or detected viral RNA in thymus of mice inoculated with CV-B3 [Klingel et al., 1996] but, to the best of our knowledge, it is the first time that a study describes the ex vivo infection of foetal mouse thymus with a CV-B. Altogether, these data clearly demonstrate the permissiveness of mouse thymus to CV-B infections.

The present study demonstrates that CV-B4 E2 replicates in murine foetal thymus organ cultures as evidenced by the detection of negative-stranded RNA within CV-B4 E2-infected lobes, and by the release of infectious particles in culture supernatants. CV-B4 E2 infection was productive, characterised by a 10 -fold increase in supernatant viral titre and a 15 - to 20 -fold increase in intracellular CV-B4 RNA copies number within foetal thymus organ cultures on day 3 compared with the residual levels on day 0 p.i., followed by decreased values of viral titre and RNA copies number on day 7, without total viral clearance. By contrast, when thymus lobes were infected with the prototype CV-B4 JVB strain, the levels of infectious particles in culture supernatants, and the numbers of RNA copies within infected lobes decreased from day 0 to day 7 p.i. Thus it appeared that CV-B4 JVB did not infect thymic lobes or at a very low level not detected in those experiments (data not shown).

In the present investigation no significant difference was observed between intracellular positive- and negative-strand RNA amounts, except on day 3 when the level of negative-strand RNA was twice as high as the one of positive-strand RNA. In other systems, the level of negative-strand RNA is usually lower than the one of positive-strand RNA. Indeed, in a previous study of human foetal thymus infected with CV-B4 E2, the positive- to negative-strand RNA ratio ranged between 3 and 5 [Brilot et al., 2004]. That ratio ranged between 1 and 3.5 in a murine thymic epithelial cell line, and was higher in the Hep-2 cell line, as assessed by quantitative real time RT-PCR (Hober et al., unpublished data). The production of equal amounts of positive and negative RNA strands has been observed in persistently infected myocardial cells [Klingel et al., 1992] in which viral gene expression is decreased, reflecting restricted viral RNA synthesis [Kandolf et al., 1999]. It has also been shown that the infection of myoblasts with CV-B1 resulted in the formation of stable double-stranded RNA complexes [Tam and Messner, 1999]. In those studies, the acute infection was over and persistence of viral RNA occurred in the absence of infectious virus production. In the current model in which cultures have been examined for 7 days p.i., with infectious virus production on day 3 p.i., one possible explanation for the balanced levels of intracellular negative and positive RNA strands, is the relatively low level of CV-B4 E2 replication in murine foetal thymus organ cultures, in so far as the levels of intracellular viral RNA per ng of total RNA is $10^{3}$ - to $10^{5}$ fold lower than the ones obtained in human Hep-2 cells infected with CV-B4 E2 (Hober et al., unpublished data).
In the current investigation, CV-B4 E2 infection did not damage the architecture of foetal thymic tissue and did not induce any obvious cell lysis, which is reminiscent of previously described in vitro studies of CV-B infections without cytopathic effect in human thymic epithelial cells [Brilot et al., 2002], pancreatic $\beta$-cells [Yoon et al., 1978; Chehadeh et al., 2000a], lymphoid cell lines [Matteucci et al., 1985], glomerular and tubular cells, or vascular endothelial cells [Conaldi et al., 1997a,b]. Altogether these data show that CV-B can infect various tissues without dramatic cell lysis in contrast with the effect of those viruses in continuous epithelial cell lines such as Hep-2, Vero and KB. In a previous investigation performed with human foetal thymus, cytopathic effect of CV-B4 E2 was observed with lower virus doses (6- to 60-fold), whereas viral replication was higher compared with that in murine foetal thymus organ cultures, since the levels of intracellular viral RNA were in continual increase until day 7 p.i. reaching $55 \times 10^{3}$ copies of positive-stranded RNA per ng of total RNA [Brilot et al., 2004].

The difference of results obtained between the murine foetal thymus organ cultures and the human foetal thymus systems can be due to the fact that mouse foetal thymic lobes were not disrupted and used as a whole, whereas human foetal thymi were dissected into small pieces, which can make cells more accessible to the virus, in so far as it has been reported that dispersing cells from tissues increases virus infectivity [Rotbart and Kirkegaard, 1992]. An alternative explanation is that murine foetal thymic cells are more resistant to CVB4 E2 infection than human foetal thymic cells, given that this virus is a human pathogen which has not been adapted previously to murine cells in the current experiments. These differences explain why CV-B4 E2 infection of murine foetal thymus organ cultures did not result in severe thymocyte depletion such as that observed in the previous investigation on human foetal thymus [Brilot et al., 2004].

In contrast with the silent effect of CV-B4 E2 infection on survival and on tissue integrity in the murine foetal thymus organ cultures system, a disturbance of thymocyte differentiation was noticed. Maturation and differentiation of $\mathrm{T}$ cells were different between CV-B4 E2infected and mock-infected foetal thymus organ cultures. Increased percentages of mature $\mathrm{CD} 4^{+}$cells and $\mathrm{CD}^{+}$cells were observed and the percentage of $\mathrm{DN}$ cells increased, whereas the percentage of immature DP cells decreased. These data suggest that CV-B4 E2 infection of the murine foetal thymus may exert an impact on two checkpoints of T-cell differentiation: first on early differentiation from DN to DP T cells, and secondly on positive selection of single positive SP CD4+ and CD8+ from DP $\mathrm{T}$ cells. Changes in the maturation of lymphocytes in foetal thymus organ cultures infected with the prototype CV-B4 JVB strain have been studied. There was no significant effect with that virus, which is in agreement with the absence (or very low level) of infection with that non-diabetogenic strain (data not shown). 
In the present model of murine foetal thymus organ cultures, thymocyte profiles were unchanged in cultures infected with UV-irradiated or antibody-neutralized CV-B4 E2 compared to mock-infected cultures (data not shown), demonstrating that that effect on thymocyte differentiation was directly and specifically associated with virus replication.

The marked increase in the percentage of $\mathrm{DN}$ cells in CV-B4-infected foetal thymus organ cultures obtained in the current study is in agreement with a $150 \%$ increase in thymic DN cells observed by Chatterjee et al. [1992] in CV-B4 E2-infected adult mice which preceded the onset of hyperglycaemia in those animals. Altogether these data raise the question of the role of thymus disorders resulting from viral infections in the pathogenesis of type 1 diabetes. The role of alterations in T lymphocyte subsets in the development of the disease cannot be excluded in so far as they have been observed in NOD mice, BB rats and diabetic patients [Jackson et al., 1981; Poussier et al., 1982; Johnston et al., 1988; Faustman et al., 1991; Zipris et al., 1991]. Whether CVB4-induced disturbances of thymic cells during foetal life can play a role in type 1 diabetes pathogenesis, by impairing T-cell differentiation, central self-tolerance and homeostasis, should be investigated further.

Since a vertical transmission of CV-B has been reported in mice models [Drouhet and Leventis, 1968; Modlin and Crumpacker, 1982; Pavlenko et al., 1992; Abzug et al., 1997], further work should be performed in order to determine whether murine foetal thymus can be infected in vivo, and whether the infection of that organ in utero can play a role in the development of autoimmune diseases such as type 1 diabetes.

The mechanism by which CV-B4 infection disturbs the thymocyte subpopulations in the murine foetal thymus organ cultures is still unclear. Based on the results of the current study, further investigations should be performed ex vivo to study the infection of murine foetal thymus with viruses like CV-B4 E2, and its consequences onto thymic functions. The murine foetal thymus organ cultures system opens up the possibility to determine factors that can affect T-cell differentiation, especially viruses.

In conclusion, the present study shows that the ex vivo infection of foetal thymus organ cultures from CD-1 mice with CV-B4 E2 has an impact on T-cell differentiation in that system.

\section{ACKNOWLEDGMENTS}

Fabienne Brilot is currently a postdoctoral fellow at the Department of Microbiology-Immunology (Christain Munz) of the Rockefeller University, New York. Hela Jaïdane was supported by the Comité Mixte de Coopération Universitaire (CMCU) with grants from Egide Paris. Vincent Geenen is a Research Professor at the National Fund of Scientific Research (Belgium). This work was supported by University Lille 2 (UPRES EA3610) and CHRU Lille, France, and the EU FP6 Integrated Project EURO-THYMAIDE (Contract LSHB-CT-2003-503410).

\section{REFERENCES}

Abzug MJ. 1997. Maternal factors affecting the integrity of the late gestation placental barrier to murine enterovirus infection. J Infect Dis 176:41-49.

Bonyhadi ML, Su L, Auten J, McCune JM, Kaneshima H. 1995 Development of a human thymic organ culture model for the study of HIV pathogenesis. AIDS Res Hum Retrovir 11:1073-1080.

Brilot F, Chehadeh W, Charlet-Renard C, Martens H, Geenen V, Hober D. 2002. Persistent infection of human thymic epithelial cells by coxsackievirus B4. J Virol 76:5260-5265.

Brilot F, Geenen V, Hober D, Stoddart CA. 2004. Coxsackievirus B4 infection of human fetal thymus cells. J Virol 78:9854-9861.

Chatterjee NK, Hou J, Dockstader P, Charbonneau T. 1992. Coxsackievirus [4B] infection alters thymic, splenic, and peripheral lymphocyte repertoire preceding onset of hyperglycemia in mice. J Med Virol 38:124-131.

Chehadeh W, Kerr-Conte J, Pattou F, Alm G, Lefebvre J, Wattre P, Hober D. 2000a. Persistent infection of human pancreatic islets by coxsackievirus B is associated with alpha interferon synthesis in beta cells. J Virol 74:10153-10164.

Chehadeh W, Weill J, Vantyghem MC, Alm G, Lefebvre J, Wattre P, Hober D. 2000b. Increased level of interferon-alpha in blood of patients with insulin-dependent diabetes mellitus: Relationship with coxsackievirus B infection. J Infect Dis 181:1929-1939.

Choudhary SK, Choudhary NR, Kimbrell KC, Colasanti J, Ziogas A, Kwa D, Schuitemaker H, Camerini D. 2005. R5 human immunodeficiency virus type 1 infection of fetal thymic organ culture induces cytokine and CCR5 expression. J Virol 79:458-471.

Conaldi PG, Biancone L, Bottelli A, De Martino A, Camussi G, Toniolo A. 1997a. Distinct pathogenic effects of group B coxsackieviruses on human glomerular and tubular kidney cells. J Virol 71:9180-9187.

Conaldi PG, Serra C, Mossa A, Falcone V, Basolo F, Camussi G, Dolei A, Toniolo A. 1997b. Persistent infection of human vascular endothelial cells by group B coxsackieviruses. J Infect Dis 175:693-696.

Dahlquist G, Frisk G, Ivarsson SA, Svanberg L, Forsgren M, Diderholm H. 1995. Indications that maternal coxsackie B virus infection during pregnancy is a risk factor for childhood-onset IDDM Diabetologia 38:1371-1373.

Drouhet V, Leventis F. 1968. Transplacental passage of Coxsackie B3 virus in pregnant mice and fetal contamination in utero. Ann Inst Pasteur 114:249-261.

Faustman D, Schoenfeld D, Ziegler R. 1991. T lymphocyte changes linked to autoantibodies. Diabetes 40:590-597.

Gamble DR, Taylor KW, Cumming H. 1973. Coxsackie viruses and diabetes mellitus. Br Med J 4:260-262.

Geenen V, Kroemer G. 1993. Multiple ways to cellular immune tolerance. Immunol Today 14:573-575.

Geenen V, Kecha O, Brilot F, Hansenne I, Renard C, Martens H. 2001. Thymic T-cell tolerance of neuroendocrine functions: Physiology and pathophysiology. Cell Mol Biol 47:179-188.

Greiner DL, Shultz LD, Deluca D, Leif JH, Christianson SW, Hesselton RM. 1996. HIV-1 infectivity of human T cells in a human/murine chimeric fetal thymic organ culture system. In Vivo 10:33-37.

Helfand RF, Gary HE, Freeman CY, Anderson LJ. Pittsburgh Diabetes Research Group, Pallansch MA. 1995. Serologic evidence of an association between enteroviruses and the onset of type 1 diabetes mellitus. J Infect Dis 172:1206-1211.

Hyöty H. 2002. Enterovirus infections and type 1 diabetes. Ann Med $34: 138-147$.

Hyöty H, Hiltunen M, Knip M, Hiltunen M, Knip M, Laakkonen M, Vahasalo P, Karjalainen J, Koskela P, Roivainen M, Leinikki P Hovi T, et al. 1995. A prospective study of the role of coxsackie $B$ and other enterovirus infections in the pathogenesis of IDDM. Diabetes 44:652-657.

Iwasaki T, Monma N, Satodate R, Kawana R, Kurata T. 1985. An immunofluorescent study of generalized coxsackie virus B3 infection in a newborn infant. Acta Pathol Jpn 35:741-748.

Jackson R, Rassi N, Crump T, Haynes B, Eisenbarth GS. 1981. The BB diabetic rat: Profound T cell lymphocytopenia. Diabetes 30:887889 .

Johnston C, Alviggi L, Millward BA, David R, Leslie G, Pyke DA Vergani D. 1988. Alterations in T lymphocyte subpopulations in type 1 diabetes. Diabetes 37:1484-1488.

Kandolf R, Sauter M, Aepinus C, Schnorr JJ, Selinka HC, Klingel K. 1999. Mechanisms and consequences of enterovirus persistence in 
cardiac myocytes and cells of the immune system. Virus Res 62:149-158.

Kecha O, Brilot F, Martens H, Franchimont N, Renard C, Greimers R, Defresne MP, Winkler R, Geenen V. 2000. Involvement of insulinlike growth factors in early T cell development: A study using fetal thymic organ cultures. Endocrinology 141:1209-1217.

King CC, Jamieson BD, Reddy K, Bali N, Concepcion RJ, Ahmed R. 1992. Viral infection of the thymus. J Virol 66:3155-3160.

Klingel K, Hohenadl C, Canu A, Albrecht M, Seemann M, Mall G, Kandolf R. 1992. Ongoing enterovirus-induced myocarditis is associated with persistent heart muscle infection: Quantitative analysis of virus replication, tissue damage and inflammation. Proc Natl Acad Sci 89:314-318.

Klingel K, Stephan S, Sauter M, Zell R, McManus BM, Bultmann B, Kandolf R. 1996. Pathogenesis of murine enterovirus myocarditis: Virus dissemination and immune cell targets. J Virol 70:88888895.

Korostoff JM, Nakada MT, Faas SJ, Blank KJ, Gaulton GN. 1990 Neonatal exposure to thymotropic gross murine leukemia virus induces virus-specific immunologic nonresponsiveness. J Exp Med 172:1765-1775.

Leparc I, Aymard M, Fuchs F. 1994. Acute, chronic and persistent enterovirus and poliovirus infections: Detection of viral genome by semi-nested PCR amplification in culture-negative samples. Mol Cell Probes 8:487-495.

Lozovskaia LS, Osipov SM, Zubkova IV, Soboleva VD. 1997. Study of vertical transmission of coxsackie group enteroviruses in the etiology of congenital immunodeficiencies. Vopr Virusol 42:175-179.

Martens H, Malgrange B, Robert F, Charlet C, De Groote D, Heymann D, Godard A, Soulillou JP, Moonen G, Geenen V. 1996. Cytokine production by human thymic epithelial cells: Control by the immune recognition of the neurohypophysial self-antigen. Regul Pept 67:39-45.

Matteucci D, Paglianti M, Giangregorio AM, Capobianchi MR, Dianzani F, Bendinelli M. 1985. Group B coxsackieviruses readily establish persistent infections in human lymphoid cell lines. J Virol 56:651-654.

Modlin JF, Crumpacker CS. 1982. Coxsackievirus B infection in pregnant mice and transplacental infection of the fetus. Infect Immun 37:222-226.
Otonkoski T, Roivainen M, Vaarala O, Dinesen B, Leipala JA, Hovi T, Knip M. 2000. Neonatal type I diabetes associated with maternal echovirus 6 infection: A case report. Diabetologia 43:1235-1238.

Owens BM, Hawley RG, Spain LM. 2005. Retroviral transduction in fetal thymic organ culture. Methods Mol Med 105:311-322.

Pavlenko LV, Evtushenko AI, Shirobokov VP. 1992. The effect of a Coxsackie viral infection on the chromosomal apparatus of the cells of fetuses and newborn mice. Mikrobiol Zh 54:59-62.

Plum J, De Smedt M, Leclercq G, Vandekerckhove B. 1995. Influence of TGF-b on murine thymocyte development in fetal thymus organ culture. J Immunol 154:5789-5798.

Poussier P, Nakhouda AF, Falk JF, Lee C, Marliss EB. 1982. Lymphopenia and abnormal lymphocyte subsets in the BB rat: Relationship to the diabetic syndrome. Endocrinology 110:1825-1827.

Reed LJ, Muench H. 1938. A simple method of estimating fifty percent endpoints. Am J Hyg 27:493-497.

Rotbart HA, Kirkegaard K. 1992. Picornavirus pathogenesis: Viral access, attachment and entry into susceptible cells. Semin Virol 3:483-499.

Selinka HC, Huber M, Pasch A, Klingel K, Aepinu C, Kandolf R. 1998. Coxsackie B virus and its interaction with permissive host cells. Clin Diagn Virol 9:115-123.

Shih FF, Mandik-Nayak L, Wipke BT, Allen PM. 2004. Massive thymic deletion results in systemic autoimmunity through elimination of CD4 ${ }^{+}$CD25 ${ }^{+}$T regulatory cells. J Exp Med 199:323-335.

Sinha AA, Lopez MT, McDevitt HO. 1990. Autoimmune diseases: The failure of self tolerance. Science 248:1380-1388.

Tam PE, Messner RP. 1999. Molecular mechanisms of coxsackievirus persistence in chronic inflammatory myopathy: Viral RNA persists through formation of a double-stranded complex without associated genomic mutations or evolution. J Virol 73:10113-10121.

Yoon JW, Onodera T, Jenson AB, Notkins AL. 1978. Virus induced diabetes mellitus XI. Replication of coxsackie B3 in human pancreatic beta cell cultures. Diabetes 27:778-781.

Yoon JW, Austin M, Onodera T, Notkins AL. 1979. Isolation of a virus from the pancreas of a child with diabetic ketoacidosis (virusinduced diabetes mellitus). New Engl J Med 300:1173-1179.

Zipris D, Crow AR, Delovitch TL. 1991. Altered thymic and peripheral T-lymphocyte repertoire preceding onset of diabetes in NOD mice. Diabetes 40:429-435. 